\title{
ON ADEQUACY OF THE MATHEMATICAL MODEL OF THE OPTIMAL DYNAMIC MEASUREMENT
}

Yu. V. Khudyakov, South Ural State University, Chelyabinsk, Russian Federation, hudyakov74@gmail.com

\begin{abstract}
We propose an approach to increase the adequacy of the mathematical model of an optimal dynamic measurement. The approach is based on obtaining additional information about the measured process. The information is presented by a set of admissible measurements. We are the first to consider a set of admissible measurements as an intersection of convex sets, where each set characterizes the measured process on a given time interval or part of the interval. The model of optimal dynamic measurements allows numerically reconstruct a dynamically distorted signal as a solution to the problem of optimal control. The model of optimal measurements contains the following elements: 1) the Leontief type system modeling a measuring device (MD); 2) the initial Showalter-Sidorov condition specifying the initial state of the measuring device; 3) the functional of quality, which is used, first of all, to achieve the proximity of real and virtual measurements; 4) the criterion of optimality, that is a search for the minimum value of the quality functional and the optimal measurement at which the value is achieved; 5) the set of admissible optimal measurements, which contains the optimal dynamic measurement. We suggest changes in the numerical algorithm proposed by the author earlier. A new version takes into account the importance of the available information on the set of admissible measurements. The results of computational experiments are presented.
\end{abstract}

Keywords: Leontief type system; theory of optimal dynamic measurements; optimal control; set of admissible measurements.

\section{Introduction}

In the papers $[1,2]$ A. L. Shestakov and G. A. Sviridyuk proposed the mathematical model of optimal dynamic measurement. We present the model in the first paragraph. The adequacy of any mathematical model is inseparably connected with the object or process investigated with the help of the model. Therefore, we construct a mathematical model of optimal dynamic measurement and its adequacy taking into account the physical point of view about the measured process and technical information on the object or the environment in which the process take place. The second paragraph considers changes in the numerical algorithm, which was proposed by the author earlier in [3]. These changes allow to take into account a priori information reflected by the set of admissible measurements. The results of computational experiments for cases with different a priori information for the same model of measuring device are presented.

Our purpose is to present the results of new studies of the mathematical model for an optimal dynamic measurement from the point of view of development of both qualitative and quantitative methods of the optimal measurements theory [4]. Another approach to improve the adequacy of models of the optimal measurements theory can be found, for example, in the works $[5,6]$. 


\section{Mathematical Model of Optimal Dynamic Measurement}

The distortions of a measured value appear during the dynamic measurements of the real process because of the following reasons: 1) the influence of the object and (or) the environment, where the process takes place; 2) the inertia of the measuring device; 3) the influence of interferences appeared at the input of the measuring device; 4) the influence of interferences appeared at the output of the measuring device; 5) equipping the object with measuring transducers, which influence the process under study; 6) limitations of measuring devices on dynamic characteristics.

In order to construct the mathematical model of optimal dynamic measurement, we need to point out the main reasons of distortions, while the remaining reasons, which are considered secondary, should not be taken into account.

Note that the complete mathematical model of optimal dynamic measurement includes the object or the environment within which the measured process takes place; the model of the primary measuring transducer, along with the associated devices; the architecture of the measuring device that converts the measured value into an observable signal. When we construct this mathematical model, it is naturally to obtain a Leontief type model. This is because algebraic relations appeared at the interfaces between «measured value», «environment » and «measuring transducer». However, inclusion of them in the mathematical model of measuring device leads to the degeneracy of the system. That is, the classical methods can not be use to investigate the system. Moreover, usually the dynamic measurements are carried out to describe the processes under study.

Figure 1 shows a diagram reflecting the structural relationships between the elements of the mathematical model of optimal measurement and the simulated processes and objects.

Assume that $L$ and $M$ are square matrices of order $n$ (and, may be, $\operatorname{det} L=0$ ), matrix $M$ is $(L, p)$-regular, $u:[0, \tau] \rightarrow \mathbb{R}^{n}$, the system of equations (1) describes a measuring device (MD)

$$
\left\{\begin{aligned}
L \dot{x} & =A x+B(u+\widetilde{\eta}), \\
y & =C x+D \eta
\end{aligned}\right.
$$

where $x(t)$ and $\dot{x}(t)$ are vector-functions of the state and the velocity of MD state change, respectively; $y(t)$ is a vector-function of observations; $L$ and $M$ are square matrices that represent the mutual influence of MD state velocities and the mutual influence of MD states, respectively; $C$ and $D$ are rectangular matrices characterizing the relationship between the system state and observation; $u+\widetilde{\eta}$ is a vector-function that includes both measurements $u(t)$ (see Fig. 1) and interferences $\widetilde{\eta}(t)$ in the circuits of the measuring device (see Fig. 1$) ; \eta(t)$ is a vector-function of the interferences at the output of the measuring device (see Fig. 1).

The second structural element of the model is the initial Showalter-Sidorov condition [7]

$$
\left[(\alpha L-A)^{-1} L\right]^{p+1}\left(x(0)-x_{0}\right)=0
$$

which for some $x_{0} \in \mathbb{R}^{n}, \alpha \in \rho^{L}(M)$ reflects the initial state of the measuring device. 


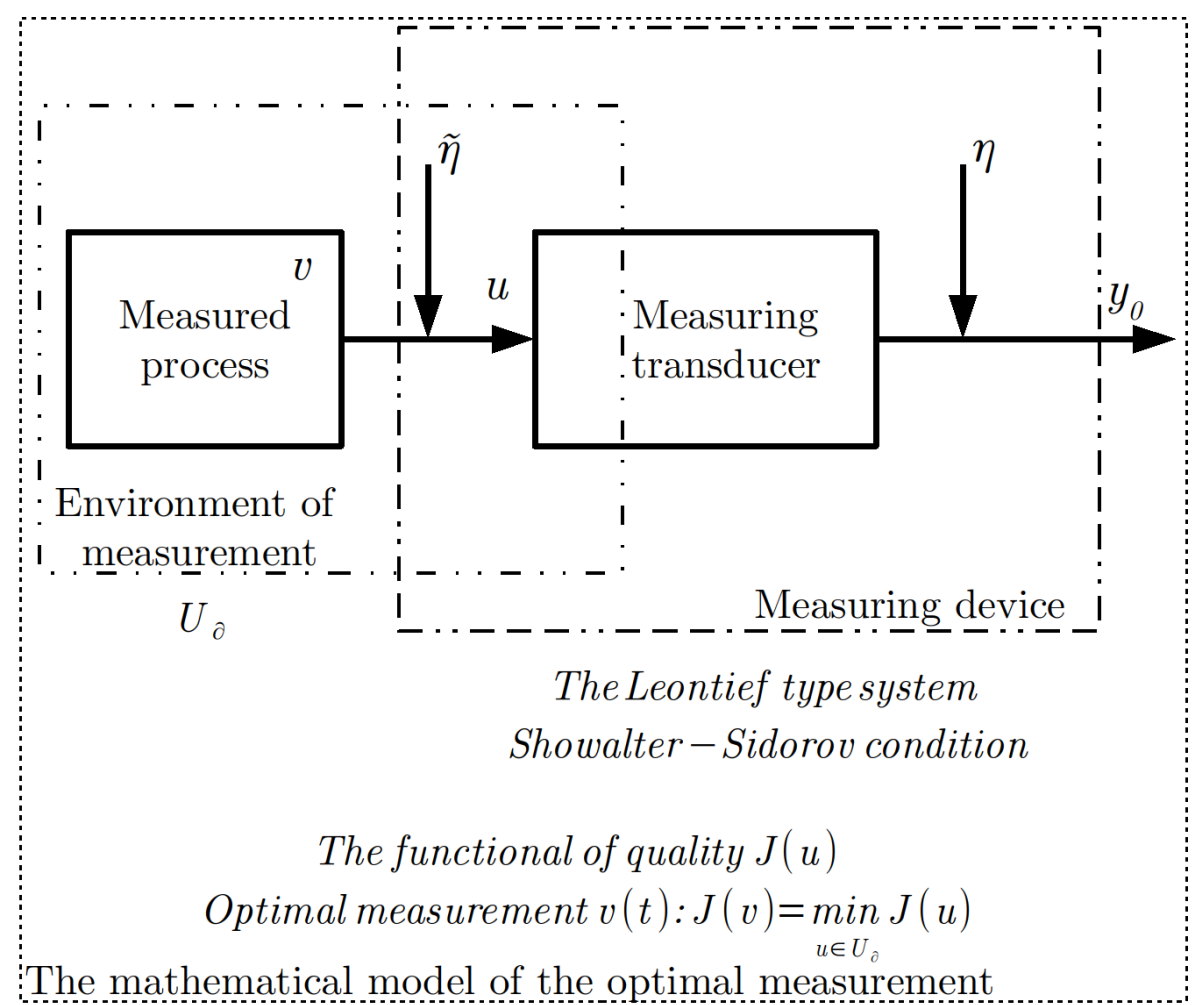

Fig. 1. Structural diagram of the mathematical model of optimal measurement

In fact, (1) and (2) represent the mathematical model of measuring device, which is shown in Fig. 1.

The main idea of the mathematical model of optimal measurement is to use the methods of the optimal control theory. Therefore,

- on the interval $[0, \tau]$ we introduce space of states $\chi=$ $\left\{x \in L_{2}\left((0, \tau), \mathbb{R}^{n}\right): \dot{x} \in L_{2}\left((0, \tau), \mathbb{R}^{n}\right)\right\}$, space of measurements $\mathfrak{U}=$ $\left\{u \in L_{2}\left((0, \tau), \mathbb{R}^{n}\right): u^{(p+1)} \in L_{2}\left((0, \tau), \mathbb{R}^{n}\right)\right\}$ and space of observations $\mathfrak{Y}=C[\chi]$.

- we construct a measurement quality functional that is an estimate of closeness of the values observed at the output of the measuring device $y_{0}(t)$ and the values of «virtual observation» $y(t)$ obtained on the basis of the mathematical model of measuring device.

In this case, the values of «virtual measurement $\gg u(t)$ at the input of the mathematical model of measuring device and the values of «virtual optimal measurement $\gg v(t)$ are also different a little. Also, the ratio between the values of the observed signal and the state of MD takes place. This key idea is reflected in the measurement quality functional, which is represented in the general form:

$$
J(u)=\beta J_{1}\left(y(u, \widetilde{\eta}, \eta, t)-y_{0}(t)\right)+(1-\beta) J_{2}(u, \widetilde{\eta}),
$$

as well as in the search for a vector-function $v \in \mathfrak{U}_{\partial}$, that minimizes the value of the functional (3)

$$
J(v)=\min _{u \in \mathfrak{U}_{\partial}} J(u)
$$

where $\beta \in[0,1]$. 
An integral part of the optimal measurement model is the set of admissible measurements $\mathfrak{U}_{\partial}$, which is essentially a compact convex subset in the space of observations $\mathfrak{U}$. As admissible measurements, we consider measurements such that

$$
\sum_{q=0}^{\theta} \int_{0}^{\tau}\left\|u^{(q)}(t)\right\|^{2} d t \leq d
$$

where $\theta$ can take integer values from 0 to $p+1$. Note that the time integral of the square of measured process is an energy released during this process in the time interval $[0, \tau]$. The integral form of the set of admissible measurements allows to use a priori information about the character of the measured process in time. This information can be obtained on the basis of the laboratory experiments, the physical model and the values of its parameters, etc. Moreover, this information allows additionally select the time intervals $\left[0, \tau_{1}\right],\left[0, \tau_{2}\right]$, $\ldots,[0, \tau]$, reflecting some stages of the process, as well as to give estimates of the set of admissible measurements on each of these intervals $d_{1}, d_{2}, \ldots, d$, respectively. Therefore, as the set of admissible measurements we take

$$
\mathfrak{U}_{\partial}=\cap \mathfrak{U}_{\partial i}=\cap\left(\sum_{q=0}^{\theta} \int_{0}^{\tau_{i}}\left\|u^{(q)}(t)\right\|^{2} d t \leq d_{i}\right) .
$$

Note that the intersection of convex sets is a convex set. Therefore, (6) defines a convex set of admissible measurements. Also, the more exactness of the estimates $d_{1}, d_{2}, \ldots, d$, the more significance of use the set of admissible measurements as a measure of adequacy of the optimal measurement model at various stages of the measured process.

Let us give an example for combustion chambers. We compare the speed and volume of fuel mixture delivery to the chamber. Then, for the expected calculated energy and the combustion speed, time intervals can be pointed out. These time intervals determine the stages of the combustion process, which allow to estimate the amount of energy released at these intervals. In this case, we can use the data of laboratory experiments, data of physical process models, etc. In the combustion process, conditionally, we distinguish two phases. The first phase is a transition process or combustion beginning. The second phase is an operating mode of the mixture combustion in the combustion chamber. The transition process begins at the moment of ignition, while igniting both the operating mixture that is contained before the start of the process, and the mixture, incoming during this phase. The operating mode of combustion begins from the moment when both the volume of the combustible operating mixture and the pressure in the chamber become constant in time. Using the information on these phases, we can define more exactly or add the conditions to the set of admissible measurements. It allows additionally increase the exactness of virtual dynamic measurements.

\section{Numerical Algorithm and Computational Experiments}

In order to define the criterion for the numerical algorithm stop, the following condition is used in [8]:

$$
\left|J\left(\widehat{v}^{\kappa}\right)-J\left(\widehat{v}^{\kappa-1}\right)\right|<\varepsilon
$$


where $\widehat{v}^{\kappa}$ is an approximate solution on the $\kappa$-th iteration. If the constants $d_{1}, d_{2}, \ldots, d$ are precisely defined in the conditions for a set of admissible measurements, we can take the following difference as a measure for the adequacy of the mathematical model:

$$
d-d^{*}=d-\sum_{q=0}^{\theta} \int_{0}^{\tau}\left\|\widehat{v}^{(q)}(t)\right\|^{2} d t
$$

and we can take the condition $d-d^{*}<\varepsilon$ as the stop criterion of the algorithm.

In order to carry out the computational experiments, we construct a mathematical model of measuring device specified by a transfer function

$$
W_{g}(p)=\frac{1}{\left(T_{1}^{2} p^{2}+2 \xi_{1} T_{1} p+1\right)\left(T_{2}^{2} p^{2}+2 \xi_{2} T_{2} p+1\right)\left(T_{3} p+1\right)\left(T_{4} p+1\right)}
$$

for given parameters $T_{1}=0,01 c, \xi_{1}=0,6, T_{2}=0,002 c, \xi_{2}=0,2$, $T_{3}=0,0005 c, T_{4}=0,0001 c$.

Taking into account possible interferences, the measuring device model has the form:

$$
\left\{\begin{array}{l}
\dot{x}_{1}=-x_{1}-0,9881 x_{2}+u+\widetilde{\eta} \\
\dot{x}_{2}=10000 x_{1}-119 x_{2} \\
\dot{x}_{3}=x_{2}-x_{3}-0,999204 x_{4} \\
\dot{x}_{4}=250000 x_{3}-119 x_{4} \\
\dot{x}_{5}=2000 x_{4}-2000 x_{5} \\
\dot{x}_{6}=10000 x_{5}-10000 x_{6} \\
y=x_{6}+\eta
\end{array}\right.
$$

where $x=\operatorname{col}\left(x_{1}(t), \ldots, x_{6}(t)\right)$ and $\dot{x}=\operatorname{col}\left(\dot{x}_{1}(t), \ldots, \dot{x}_{6}(t)\right)$ are vector-functions of state and velocity of MD state change, respectively, $x_{0}=\operatorname{col}(0, \ldots, 0), u(t), y(t)$ are vector-functions of the measured and observed signals of measuring device. On time interval $[0, \tau]$, taking into account the obtained value $p=0$, we define the set of admissible measurements

$$
\sum_{q=0}^{1} \int_{0}^{0,08}\left\|u_{k}^{\ell^{(q)}}\left(\widehat{a_{i j}}, t\right)\right\|^{2} d t<d=211,6097
$$

Let us consider the case when the resonance interference acts only at the output of MD. The interference frequency $\omega=5000$ is known, therefore, $\eta=a_{\omega} \sin 5000 t$. Fig. 2 . shows the observations $Y_{0}(t)$, obtained during the experiment, as well as the optimal measurement $v_{k}^{\ell}$, obtained as a result of the computational experiment. 


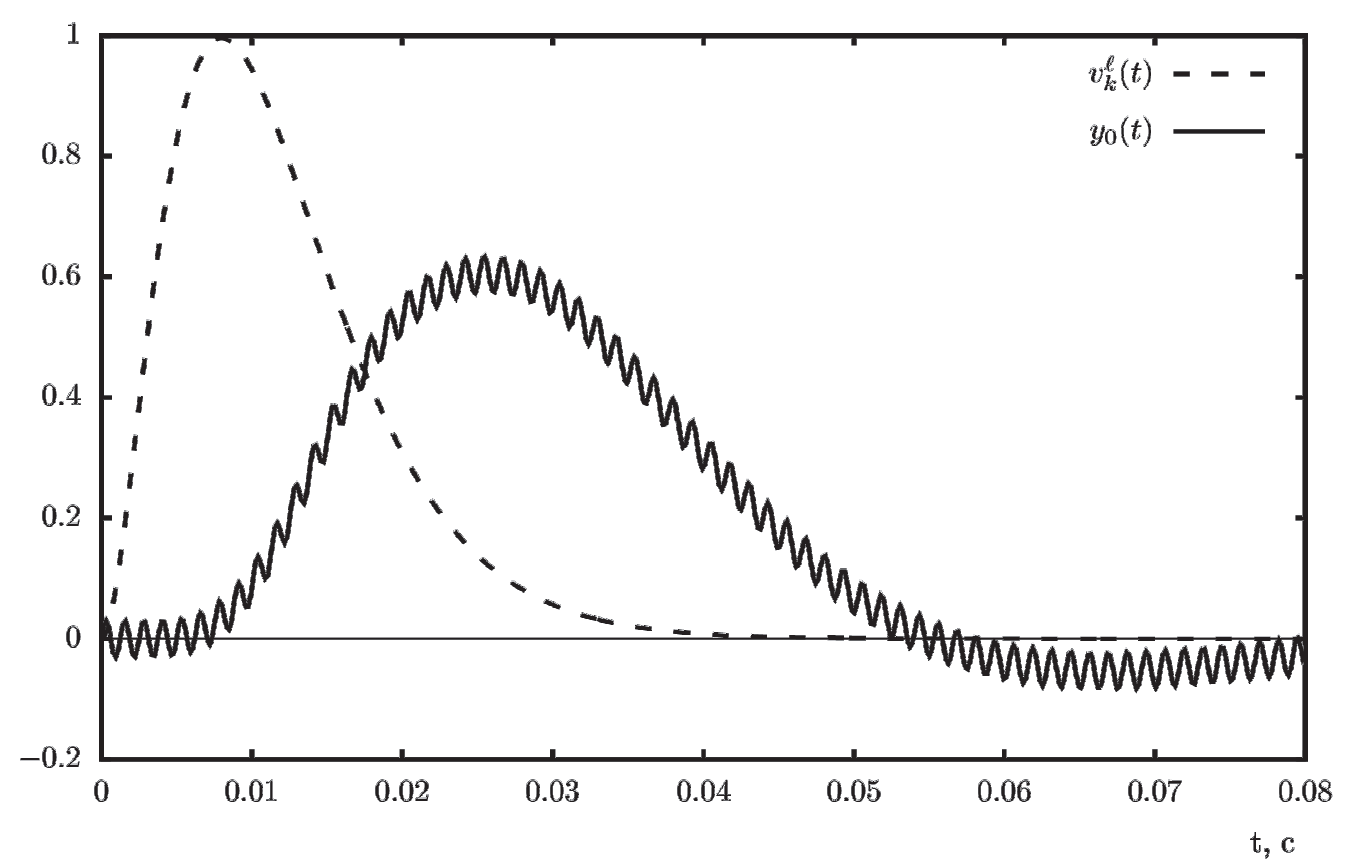

Fig. 2. Results of computational experiment for the case when a resonance interference acts at MD output with a given resonance frequency

As a result of the computational experiment, we find that the amplitude of the resonance interference is $\eta=0,030151 \sin 5000 t$. Also, we obtain an approximate solution to the problem of optimal dynamic measurement (ODM)

$$
\begin{aligned}
& v_{k}^{\ell}=0,156386711672626 \sin (2 \pi \cdot 6.25 t)+0,247407484951549 \sin (2 \pi \cdot 12,5 t)+ \\
& \quad+0,258215058876576 \sin (2 \pi \cdot 18,75 t)+0,217172530953783 \sin (2 \pi \cdot 25 t)+ \\
& \quad+0,159416960961203 \sin (2 \pi \cdot 31,25 t)+0,106420289628521 \sin (2 \pi \cdot 37,5 t)+ \\
& \quad+0,0657668934971499 \sin (2 \pi \cdot 43,75 t)+0,0374662930570334 \sin (2 \pi \cdot 50 t)+ \\
& +0,0189026694461611 \sin (2 \pi \cdot 56,25 t)+0,00722447810984459 \sin (2 \pi \cdot 62,5 t)+ \\
& +0,000141998282577822 \sin (2 \pi \cdot 68,75 t)-0,00397622330210702 \sin (2 \pi \cdot 75 t)- \\
& -0,00622392263810763 \sin (2 \pi \cdot 81,25 t)-0,00731276449005634 \sin (2 \pi \cdot 87,5 t)- \\
& -0,00769624688641762 \sin (2 \pi \cdot 93,75 t)-0,00766147606400266 \sin (2 \pi \cdot 100 t)- \\
& -0,0073875884086711 \sin (2 \pi \cdot 106,25 t)-0,00698658726010777 \sin (2 \pi \cdot 112,5 t)- \\
& -0,00652670863981444 \sin (2 \pi \cdot 118,75 t)-0,00604985771367458 \sin (2 \pi \cdot 125 t)- \\
& -0,00558016109398793 \sin (2 \pi \cdot 131,25 t)-0,00513175948284598 \sin (2 \pi \cdot 137,5 t)- \\
& -0,0047114664538241 \sin (2 \pi \cdot 143,75 t)-0,00432264179436352 \sin (2 \pi \cdot 150 t)- \\
& -0,00396554753897888 \sin (2 \pi \cdot 156,25 t)-0,00363959261079678 \sin (2 \pi \cdot 162,5 t)- \\
& -0,00334280694898749 \sin (2 \pi \cdot 168.75 t)-0,00307337823849602 \sin (2 \pi \cdot 175 t)- \\
& -0,00282880861797621 \sin (2 \pi \cdot 181,25 t)-0,00260712169018823 \sin (2 \pi \cdot 187,5 t)-
\end{aligned}
$$




$$
-0,0024059271302477 \sin (2 \pi \cdot 193,75 t)-0,00222345803520028 \sin (2 \pi \cdot 200 t) .
$$

Let us compare the exact solution to the optimal dynamic measurement problem $v(t)$ (which is known due to the model example) and the approximate solution $v_{k}^{\ell}(t)$ (Fig. 3). It is obvious that the approximate solution is quite exact, despite the number of terms in the representation by a trigonometric polynomial is small.

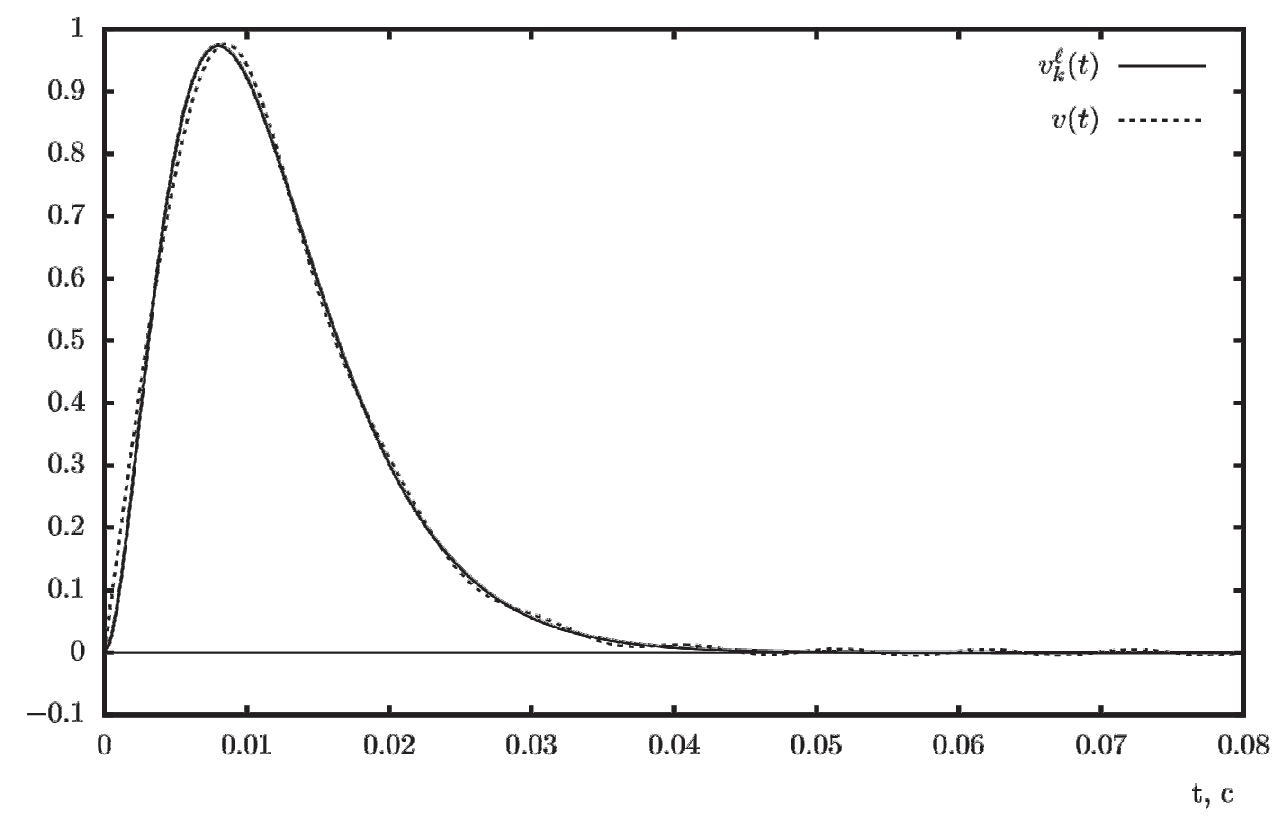

Fig. 3. Approximate and exact solutions to ODM problem of Example 1

Fig. 4 shows a graph of the difference between the exact and approximate solutions.

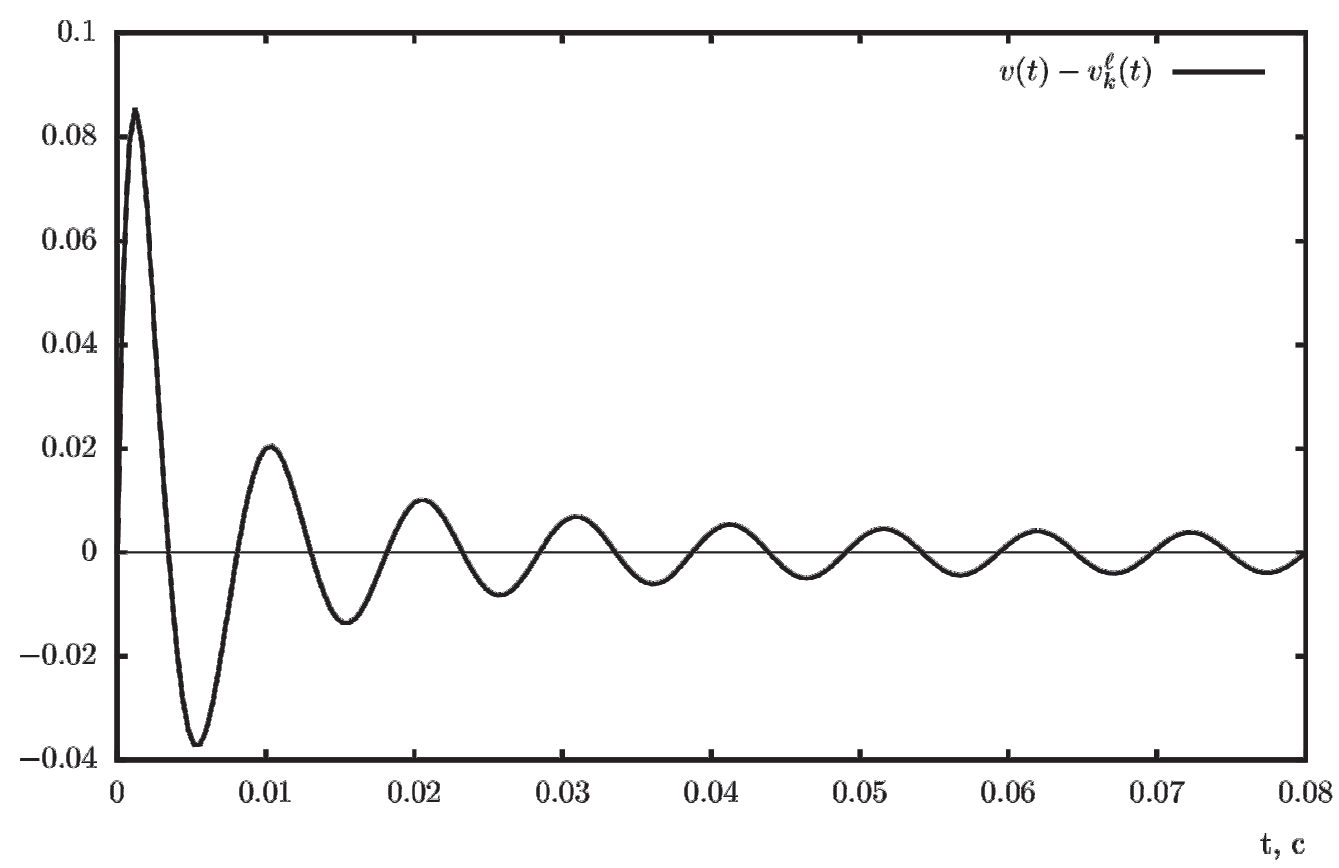

Fig. 4. Difference between the exact and approximate solutions to ODM problem of Example 1 
Note that $\max \left|v_{k}^{\ell}(t)-v(t)\right|=0.831234$. If we increase the number of terms in the trigonometric polynomial to 150 , then the error will decrease to 0.0001 , however, the calculation speed will be seriously reduced.

Let us consider the same example with other information about the measured process. Thus, on three intervals $\left[0, \tau_{1}\right],\left[\tau_{1}, \tau_{2}\right]$ and $\left[\tau_{2}, \tau_{3}\right]$, where $\tau_{1}=0,004, \tau_{2}=0,014$ and $\tau_{3}=0,04$, the restrictions for the set of admissible measurements are specified. Represent them in the following way:

$$
\begin{aligned}
& \sum_{q=0}^{1} \int_{0}^{0,004}\left\|u_{k}^{\ell^{(q)}}\left(\widehat{a_{i j}}, t\right)\right\|^{2} d t<d_{1}=123,0066, \\
& \sum_{q=0}^{1} \int_{0,004}^{0,014}\left\|u_{k}^{\ell(q)}\left(\widehat{a_{i j}^{\rho}}, t\right)\right\|^{2} d t<d_{2}=124,6636, \\
& \sum_{q=0}^{1} \int_{0,014}^{0,4}\left\|u_{k}^{\ell(q)}\left(\widehat{a_{i j}^{\rho}}, t\right)\right\|^{2} d t<d_{3}=38,9579 .
\end{aligned}
$$

For this set of admissible measurements, we obtain another solution. Fig. 5 shows the graphs of the obtained solutions to the following two problems of the optimal dynamic measurement: $v_{k}^{\ell *}$ with three conditions for the set of admissible measurements, $v_{k}^{\ell}$ with one condition for the set of admissible measurements.

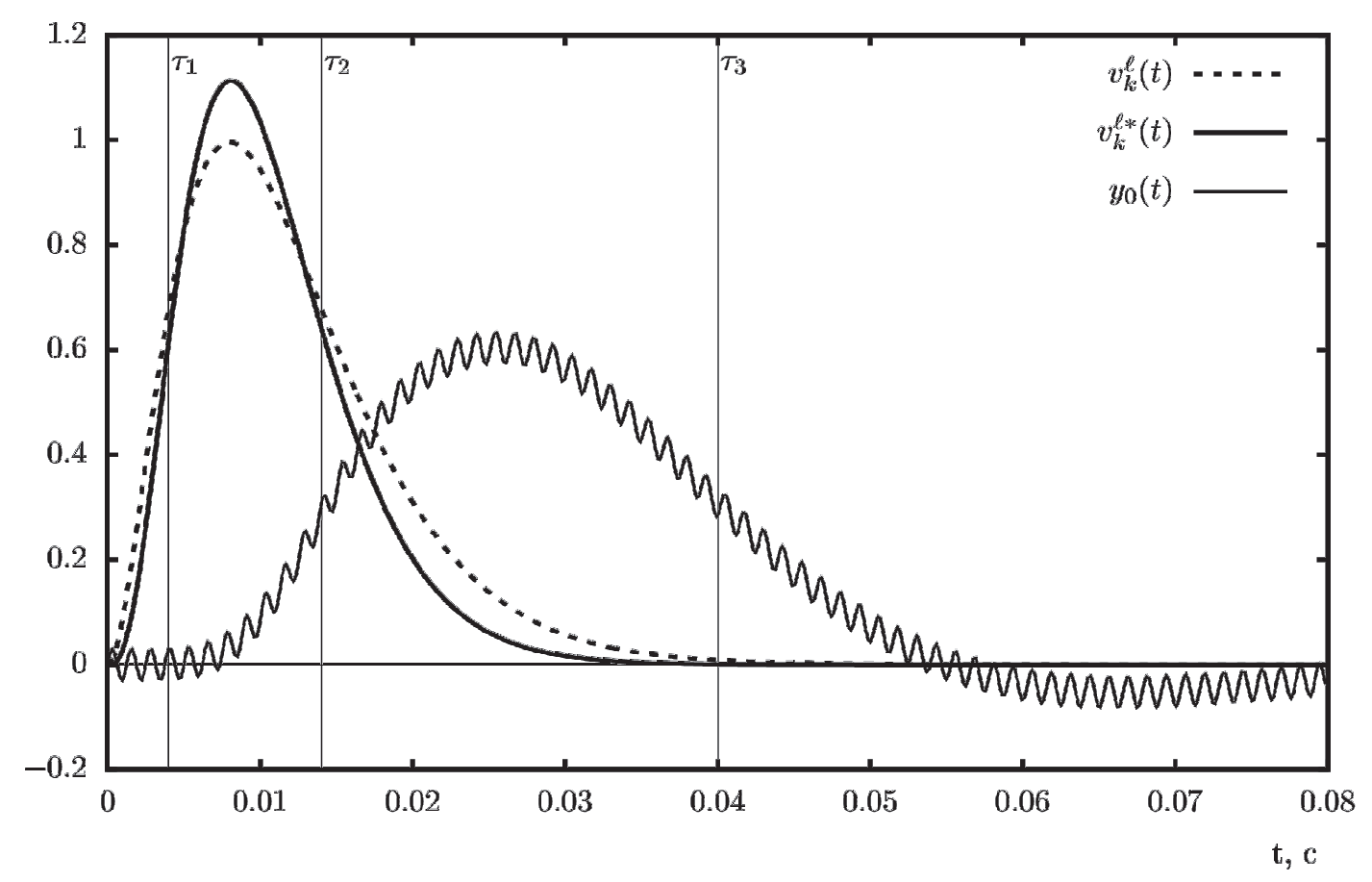

Fig. 5. Results of the computational experiment, when the set of admissible measurements is defined more exactly 
An approximate solution to the optimal dynamic measurement problem with three conditions for the set of admissible measurements has the form:

$$
\begin{aligned}
& v_{k}^{\ell *}=0,133946822595132 \sin (2 \pi \cdot 6.25 t)+0,227106835731783 \sin (2 \pi \cdot 12,5 t)+ \\
& +0,260308519624985 \sin (2 \pi \cdot 18,75 t)+0,240676528880669 \sin (2 \pi \cdot 25 t)+ \\
& +0,190163561862987 \sin (2 \pi \cdot 31,25 t)+0,131037350098669 \sin (2 \pi \cdot 37,5 t)+ \\
& +0,0779306975310919 \sin (2 \pi \cdot 43,75 t)+0,0370821746285821 \sin (2 \pi \cdot 50 t)+ \\
& +0,00903851547967552 \sin (2 \pi \cdot 56,25 t)-0,0083565680358572 \sin (2 \pi \cdot 62,5 t)- \\
& -0,0179590971351134 \sin (2 \pi \cdot 68,75 t)-0,0223438228938383 \sin (2 \pi \cdot 75 t)- \\
& -0,0234841874170562 \sin (2 \pi \cdot 81,25 t)-0,0227560650768984 \sin (2 \pi \cdot 87,5 t)- \\
& -0,0210574137313625 \sin (2 \pi \cdot 93,75 t)-0,0189433454169347 \sin (2 \pi \cdot 100 t)- \\
& -0,0167390007829702 \sin (2 \pi \cdot 106,25 t)-0,0146224962412895 \sin (2 \pi \cdot 112,5 t)- \\
& -0,0126816149042001 \sin (2 \pi \cdot 118,75 t)-0,0109507751280247 \sin (2 \pi \cdot 125 t)- \\
& -0,00943430829036674 \sin (2 \pi \cdot 131,25 t)-0,00812069903659914 \sin (2 \pi \cdot 137,5 t)- \\
& -0,00699104125599831 \sin (2 \pi \cdot 143,75 t)-0,00602389649627148 \sin (2 \pi \cdot 150 t)- \\
& -0,005197951166799 \sin (2 \pi \cdot 156,25 t)-0,00449336725212877 \sin (2 \pi \cdot 162,5 t)- \\
& -0,00389236652034175 \sin (2 \pi \cdot 168.75 t)-0,00337939039194787 \sin (2 \pi \cdot 175 t)- \\
& -0,00294102762136243 \sin (2 \pi \cdot 181,25 t)-0,00256583498378781 \sin (2 \pi \cdot 187,5 t)- \\
& -0,00224411078915205 \sin (2 \pi \cdot 193,75 t)-0,00196766549856338 \sin (2 \pi \cdot 200 t) .
\end{aligned}
$$

Note that the solutions obtained for different sets of admissible measurements correspond to different models of optimal measurement, in spite of the fact that the observations made on the same measuring device are identical. A well-known example by Edward H. Adelson (Fig. 6) shows the influence of information about the lighting of object on the result of color observation. Let us measure the color of sections A and B under the lighting conditions shown in Fig. 6, using the measurement methods without taking into account the difference in the lighting of the sections. Then, the device will show the same measurement result. In our case, it is one of the variants to construct a model of color measurement. However, if in the model we add the conditions of lighting of the sections in the set of permissible measurements as a priori information about the object, then we get another model for measuring the color of sections. With this additional information, the measuring device will show the true, i.e. different, colors of sections A and B. Note that a human eye conducts exactly this "measurement"of the sections colors. Taking into account the lighting "automatically", the eye correctly determine the colors of sections as different. However, if the eye, as a measuring device, has no this information (about the nature of the object and its lighting), then the eye correctly determines the colors of sections as the same, working under the conditions of the first model, which is less complete than the second one. 

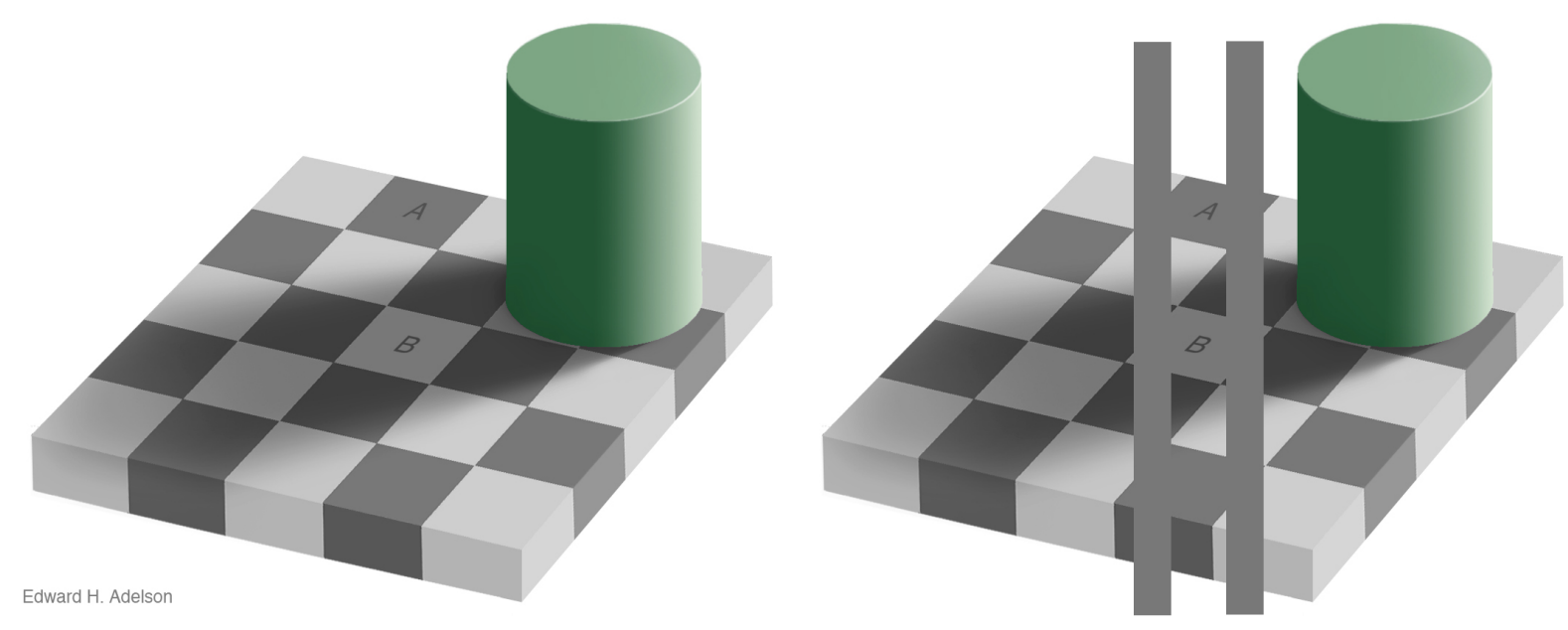

Fig. 6. Checkershadow Illusion [http://persci.mit.edu/gallery/checkershadow]

Therefore, the existence of an adequate mathematical model of measuring device does not guarantee the adequacy of the mathematical model of optimal measurement without sufficient a priori information about the measured process, reflected in the set of admissible measurements.

\section{References}

1. Shestakov A.L., Sviridyuk G.A. A New Approach to Measurement of Dynamically Perturbed Signal. Bulletin of the South Ural State University. Series: Mathematical Modelling, Programming Computer Software, 2010, no. 16 (192), issue 5, pp. 116-120. (in Russian)

2. Shestakov A.L., Sviridyuk G.A. Optimal Measurement of Dynamically Distorted Signals. Bulletin of the South Ural State University. Series: Mathematical Modelling, Programming Computer Software, 2011, no. 17 (234), issue 8, pp. 70-75.

3. Khudyakov Yu.V. The Numerical Algorithm to Investigate Shestakov-Sviridyuk's Model of Measuring Transducer with Inertia and Resonances. Mathematical Notes of NorthEastern Federal University, 2013, vol. 20, no. 2, pp. 211-221. (in Russian)

4. Keller A.V., Nazarova E.I. The Regularization Property and the Computational Solution of the Dynamic Measure Problem. Bulletin of the South Ural State University. Series: Mathematical Modelling, Programming Computer Software, 2010, no. 16 (195), issue 5, pp. 32-38. (in Russian)

5. Keller A.V., Sagadeeva M.A. The Optimal Measurement Problem for the Measurement Transducer Model with a Deterministic Multiplicative Effect and Inertia. Bulletin of the South Ural State University. Series: Mathematical Modelling, Programming and Computer Software, 2014, vol. 7, no. 1, pp. 134-138. doi: 10.14529/mmp140111 (in Russian)

6. Sagadeeva M.A. Mathematical Bases of Optimal Measurements Theory in Nonstationary Case. Journal of Computational and Engineering Mathematics, 2016, vol. 3, no. 3, pp. 19-32. doi: 10.14529/jcem160303 
7. Sviridyuk G.A., Zagrebina S.A. The Showalter-Sidorov problem as a phenomena of the Sobolev-type equations. The Bulletin of Irkutsk State University. Series Mathematics, 2010, vol. 3, no. 1, pp. 104-125. (in Russian)

8. Keller A.V., Shestakov A.L., Sviridyuk G.A., Khudyakov Y.V. The Numerical Algorithms for the Measurement of the Deterministic and Stochastic Signals. Springer Proceedings in Mathematics and Statistics, 2015, vol. 113, pp. 183-195. doi: 10.1007/978-3-319-12145-1_11

Yurii V. Khudyakov, Tutor, Department of Applied Mathematics and Programming, South Ural State University (Chelyabinsk, Russian Federation), hudyakov74@gmail.com

Received June 7, 2017

УДК 517.9

DOI: $10.14529 /$ jcem 170202

\title{
ОБ АДЕКВАТНОСТИ МАТЕМАТИЧЕСКОЙ МОДЕЛИ ОПТИМАЛЬНОГО ДИНАМИЧЕСКОГО ИЗМЕРЕНИЯ
}

\section{Ю. В. Худяков}

\begin{abstract}
В статье предложен подход повышения адекватности математической модели оптимального динамического измерения на основе получения дополнительной информации об измеряемом процессе, представляемой множеством допустимых измерений. Впервые множество допустимых измерений рассматривается как пересечение выпуклых множеств, каждое из которых характеризует измеряемый процесс на заданном временном промежутке или его части. Модель оптимальных динамических измерений позволяет численно восстанавливать динамически искаженный сигнал как решение задачи оптимального управления. Модель оптимальных динамических измерений содержит следующие элементы: 1) систему леонтьевского типа, моделирующую измерительное устройство (ИУ); 2) начальное условие Шоуолтера-Сидорова, задающее начальное состояние измерительного устройства; 3) функционал качества, смысл которого, прежде всего, заключается в достижении близости реальных и виртуальных измерений; 4) критерий оптимальности - поиск минимального значения функционала качества и оптимального измерения, при котором он достигается; 5) множество допустимых оптимальных измерений, среди которых и находится оптимальное динамическое измерение. В статье предлагаются изменения в численном алгоритме, предложенном автором ранее с учетом значимости имеющейся информации о множестве допустимых измерений. Представлены результаты вычислительных экспериментов.

Ключевые слова: система леонтьевского типа; теория оптимальных динамических измерений; оптимальное управление; множество допустимых измерений.
\end{abstract}

\section{References}

1. Шестаков, А.Л. Новый подход к измерению динамически искаженных сигналов / А.Л. Шестаков, Г.А. Свиридюк // Вестник ЮУрГУ. Серия: Математическое моделирование и программирование. - 2010. - № 16 (192), вып. 5.- С. 116-120.

2. Shestakov, A.L. Optimal measurement of dynamically distorted signals A.L. Shestakov, G.A. Sviridyuk // Вестник ЮУрГУ. Серия: Математическое моделирование и программирование. - 2011. - № 17 (234), вып. 8. - С. 70-75. 
3. Худяков, Ю.В. Алгоритм численного исследования модели ШестаковаСвиридюка измерительного устройства с инерционностью и резонансами / Ю.В. Худяков // Математические заметки СВФУ. - 2013. - Т. 20, № 2. C. 211-221.

4. Келлер, А.В. Свойство регуляризуемости и численное решение задачи динамического измерения / А.В. Келлер, Е.И. Назарова // Вестник ЮУрГУ. Серия: Математическое моделирование и программирование. - 2010. - № 16 (192). - С. 32-38.

5. Келлер, А.В. Задача оптимального измерения для модели измерительного устройства с детерминированным мультипликативным воздействием и инерционностью / А.В. Келлер, М.А. Сагадеева // Вестник ЮУрГУ. Серия: Математическое моделирование и программирование. - 2014. -№ 1. - С. 134-138.

6. Sagadeeva, M.A. Mathematical Bases of Optimal Measurements Theory in Nonstationary Case / M.A. Sagadeeva // Journal of Computational and Engineering Mathematics. - 2016. - V. 3, № 3. - P. 19-32.

7. Свиридюк, Г.А. Задача Шоуолтера-Сидорова как феномен уравнений соболевского типа / Г.А. Свиридюк, С.А. Загребина // Известия Иркутского государственного университета. Сер.: Математика. - 2010. - Т. 3, № 1. - С. 104-125.

8. Keller, A.V. The Numerical Algorithms for the Measurement of the Deterministic and Stochastic Signals / A.V. Keller, A.L. Shestakov, G.A. Sviridyuk, Y.V. Khudyakov // Springer Proceedings in Mathematics and Statistics. - 2015. - V. 113. - P. 183-195.

Худяков Юрий Владимирович, тъютор, кафедра прикладной математики и программирования, Южно-Уральский государственный университет (г. Челябинск, Российская Федерачия), hudyakov74@gmail.com

Поступила в редакцию 7 июня 2017 г. 